\title{
Special issue on information systems curriculum
}

\author{
Bill Davey
}

Published online: 24 August 2010

(C) Springer Science+Business Media, LLC 2010

Education and Information Technologies is the principal outlet for publication of research related to the interests of IFIP Technical Committee 3. This special issue is dedicated to work related to the aims of working groups 3.2 and 3.4 of TC3. Generally speaking these two groups seek to gather together the most recent thinking in vocational education and university education. In particular the aims of the groups, taken from the IFIP web site, include:

"The work in Working Group 3.2 covers all aspects of the role of informatics and resulting technologies in higher education (universities, polytechnics, colleges of higher education, institutes of technology, etc.) covering education of specialists ..."

And

“... The provision of initial and on-going IT training and education for nonICT professionals to enable them to use and contribute to the development of ICT systems."

Preparation of information systems professionals presents special challenges to the curriculum planner. Forces including current industry practice, discipline fundamentals and trends indicated by research are often at odds with the limited time available in a degree program. This special issue aims to further research into evidence based curriculum design and implementation.

The issue deals with four levels of interest to the curriculum developer:

- the relevance of new research methods to understanding curriculum changeTatnall introduces the idea of curriculum change as an innovation and argues that the research method of Actor-Network Theory is a particularly relevant approach to take in an area of complexity and rapid change

B. Davey $(\bowtie)$

School of BIT, RMIT University, Melbourne, Australia

e-mail: billd@rmit.edu.au 
- rational approaches to selection of curriculum elements-Parker and Blake detail complementary ways of thinking about decisions on software elements to be part of a curriculum

- different ways of encapsulating elements within a curriculum.-Ralevich \& Martinovic and Long \& White show two ways of approaching the integration of security issues into a curriculum

- Issues involved with making a curriculum effective-Weng, Cheong \& Cheong discuss one issue in the context of tertiary education

The first article in this issue, "Using Actor-Network Theory to Understand the Process of Information Systems Curriculum Innovation" is from Arthur Tatnall. The article proposes that actor network theory is an important research approach in studying areas that change as quickly as does the field of information systems. This methodology seeks to avoid reductionism of complex socio-technical systems such as the situation that surrounds curriculum development.

The next two articles by Parker and Blake discuss the specific issue of choosing software and programming languages. The arguments in each case revolve around logical selection for purpose. The existence of models of this type is important, as selection of software is an ongoing process in a discipline where new tools become available on a very short life cycle.

Two articles by Ralevich \& Martinovic and Long \& White explore the specific curriculum component of security. Discussions of the nature and issues surrounding major curriculum components are valuable.

Finally, an article by Weng, Cheong and Cheong examine the influence of selfefficacy and academic integration using a specific case in Asia.

The aim of this special issue is to generate continuing dialogue around the complex task of adapting and implementing curriculum in the rapidly changing information technology environment. The success of this will be judged by the continued appearance of high quality articles from this important part of the work of TC3.

Bill Davey

Associate Editor 